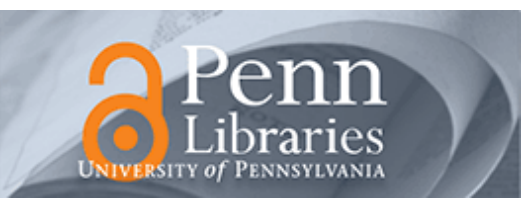

University of Pennsylvania

ScholarlyCommons

\title{
Effect of Thermal Treatments on the Transduction Behaviors of Conductometric Hydrogen Gas Sensors Integrated with $\mathrm{HCl}-$ Doped Polyaniline Nanofibers
}

\author{
Pen-Cheng Wang \\ University of Pennsylvania \\ Yaping Dan \\ University of Pennsylvania, yapingd@seas.upenn.edu \\ Luke A. Somers \\ University of Pennsylvania, Isomers@sas.upenn.edu \\ Alan G. MacDiarmid \\ University of Pennsylvania \\ A.T. Charlie Johnson \\ University of Pennsylvania, cjohnson@physics.upenn.edu
}

Follow this and additional works at: https://repository.upenn.edu/ese_papers

\section{Recommended Citation}

Pen-Cheng Wang, Yaping Dan, Luke A. Somers, Alan G. MacDiarmid, and A.T. Charlie Johnson, "Effect of Thermal Treatments on the Transduction Behaviors of Conductometric Hydrogen Gas Sensors Integrated with HCl-Doped Polyaniline Nanofibers", . January 2008.

Copyright 2008 Materials Research Society. Reprinted from:

2008. Pen-Cheng Wang, Yaping Dan, Luke A. Somers, Alan G. MacDiarmid, and A.T. Charlie Johnson. Mater. Res.

Soc. Symp. Proc. Vol. 1042, Paper \#1042-S06-06.

URL: http://www.mrs.org/s_mrs/index.asp

This paper is posted at ScholarlyCommons. https://repository.upenn.edu/ese_papers/501

For more information, please contact repository@pobox.upenn.edu. 


\title{
Effect of Thermal Treatments on the Transduction Behaviors of Conductometric Hydrogen Gas Sensors Integrated with HCl-Doped Polyaniline Nanofibers
}

\begin{abstract}
We present the effect of thermal treatments on the transduction behaviors of $\mathrm{HCl}$-doped polyaniline (PANI) nanofibers integrated in conductometric devices upon exposure to $1 \% \mathrm{H} 2$ (carried by $\mathrm{N} 2$ ). After drying in $\mathrm{N} 2$ at $25^{\circ} \mathrm{C}$ for 12 hours, devices showed a $\sim 10 \%$ decrease in electrical resistance upon exposure to $1 \% \mathrm{H} 2$. However, devices subject to 12 -hour drying in $\mathrm{N} 2$ at $25^{\circ} \mathrm{C}$ followed by further thermal treatments in $\mathrm{N} 2$ at $100^{\circ} \mathrm{C}, 164^{\circ} \mathrm{C}$ or $200^{\circ} \mathrm{C}$ for 30 minutes showed different transduction behaviors. Specifically, devices subject to thermal treatments at $100^{\circ} \mathrm{C}$ and $164^{\circ} \mathrm{C}$ showed a decrease in electrical resistance by $\sim 7 \%$ and $<0.5 \%$, respectively. More interestingly, the device subject to thermal treatment at $200^{\circ} \mathrm{C}$ showed a transduction behavior with opposite polarity, i.e. a $\sim 5 \%$ increase in electrical resistance upon exposure to $1 \% \mathrm{H} 2$. SEM, FTIR and TGA were employed to investigate the effect of thermal treatments on the morphology and chemical characteristics of HCl-doped polyaniline nanofibers. The results indicated that the change in the devices? interesting transduction behaviors might be related to the thermal treatment effects on the $\mathrm{HCl}$-doped PANI nanofibers in (i) removal of adsorbed water, and (ii) crosslinking and/or degradation of polymer backbones.
\end{abstract}

\section{Keywords}

Heat treatment, Bacteriophages, Crosslinking, Dewatering, Doping (additives), Electric currents, Electric resistance, Fourier transform infrared spectroscopy, Hydrogen, Hydrogen storage, Nanofibers, Polyaniline, Adsorbed water, Chemical characteristic, Conductometric, Doped polyaniline, Electrical resistances, FTIR, Hydrogen gas sensors, Polymer backbones, SEM, Thermal treatment

\section{Comments}

Copyright 2008 Materials Research Society. Reprinted from:

2008. Pen-Cheng Wang, Yaping Dan, Luke A. Somers, Alan G. MacDiarmid, and A.T. Charlie Johnson. Mater. Res. Soc. Symp. Proc. Vol. 1042, Paper \#1042-S06-06.

URL: http://www.mrs.org/s_mrs/index.asp 


\title{
Effect of Thermal Treatments on the Transduction Behaviors of Conductometric Hydrogen Gas Sensors Integrated with HCl-Doped Polyaniline Nanofibers
}

\author{
Pen-Cheng Wang ${ }^{1,2}$, Yaping $\operatorname{Dan}^{3}$, Luke A. Somers ${ }^{2}$, Alan G. MacDiarmid ${ }^{1}$, and A.T. Charlie \\ Johnson $^{2,3}$ \\ ${ }^{1}$ Department of Chemistry, University of Pennsylvania, Philadelphia, PA, 19104 \\ ${ }^{2}$ Department of Physics and Astronomy, University of Pennsylvania, Philadelphia, PA, 19104 \\ ${ }^{3}$ Department of Electrical and Systems Engineering, University of Pennsylvania, Philadelphia, \\ PA, 19104
}

\begin{abstract}
We present the effect of thermal treatments on the transduction behaviors of HCl-doped polyaniline (PANI) nanofibers integrated in conductometric devices upon exposure to $1 \% \mathrm{H}_{2}$ (carried by $\mathrm{N}_{2}$ ). After drying in $\mathrm{N}_{2}$ at $25^{\circ} \mathrm{C}$ for 12 hours, devices showed a $\sim 10 \%$ decrease in electrical resistance upon exposure to $1 \% \mathrm{H}_{2}$. However, devices subject to 12-hour drying in $\mathrm{N}_{2}$ at $25^{\circ} \mathrm{C}$ followed by further thermal treatments in $\mathrm{N}_{2}$ at $100^{\circ} \mathrm{C}, 164^{\circ} \mathrm{C}$ or $200^{\circ} \mathrm{C}$ for 30 minutes showed different transduction behaviors. Specifically, devices subject to thermal treatments at $100^{\circ} \mathrm{C}$ and $164^{\circ} \mathrm{C}$ showed a decrease in electrical resistance by $\sim 7 \%$ and $<0.5 \%$, respectively. More interestingly, the device subject to the thermal treatment at $200^{\circ} \mathrm{C}$ showed a transduction behavior with opposite polarity, i.e. a $\sim 5 \%$ increase in electrical resistance upon exposure to $1 \%$ $\mathrm{H}_{2}$. SEM, FTIR and TGA were employed to investigate the effect of thermal treatments on the morphology and chemical characteristics of HCl-doped polyaniline nanofibers. The results indicated that the change in the devices' interesting transduction behaviors might be related to the thermal treatment effects on the HCl-doped PANI nanofibers in (i) removal of adsorbed water, and (ii) crosslinking and/or degradation of polymer backbones.
\end{abstract}

\section{INTRODUCTION}

As one of the main themes in the development of hydrogen economy, hydrogen storage has become a very dynamic research area. Conducting polymers have been reported to be promising materials for this application. $[1,2]$. However, later studies on hydrogen storage using conducting polymers gave controversial results, showing either much lower $\mathrm{H}_{2}$ uptake or no $\mathrm{H}_{2}$ uptake at all [3-5]. It is believed that this controversy could be related to the ambiguous and somewhat inconsistent materials processing procedures used, as the properties of conducting polymers (e.g. oxidation states, doping levels etc) can be affected by many subtle processing variables [6]. Thus, it is of particular interest to further investigate the effects of those processing variables on the interactions between $\mathrm{H}_{2}$ and conducting polymers.

While hydrogen storage using conducting polymers is under active investigation, conductometric devices integrated with conducting polymers for $\mathrm{H}_{2}$ sensing have also been demonstrated $[7,8]$. The studies on the interactions between $\mathrm{H}_{2}$ and conducting polymers using conductometric sensors showed that conducting polymers subject to different experimental conditions could result in different transduction behaviors [7,8], which suggests that these conductometric gas sensors may be used to acquire information for the research on exploiting conducting polymers for hydrogen storage application. 
Since the controversy in hydrogen storage using PANI-based materials might be caused by the different thermal treatments on $\mathrm{HCl}$-treated PANI $[1,2,5]$, the effect of thermal treatments on the transduction behaviors of $\mathrm{HCl}$-doped PANI nanofibers integrated in conductometric devices upon exposure to $1 \% \mathrm{H}_{2}$ (carried by $\mathrm{N}_{2}$ ) at $25^{\circ} \mathrm{C}$ was investigated in this work. In addition, SEM, TGA and FITR were also used to study the morphology and chemical characteristics of $\mathrm{HCl}$-doped PANI subject to thermal treatments.

\section{EXPERIMENT DETAILS}

HCl-doped PANI nanofibers were synthesized by template-free oxidative chemical polymerization in a single-phase acidic aqueous medium [9-11]. Briefly, $10 \mathrm{ml}$ of $0.02 \mathrm{M}$ $\left(\mathrm{NH}_{4}\right)_{2} \mathrm{~S}_{2} \mathrm{O}_{8}$ in $1.0 \mathrm{M} \mathrm{HCl}_{(\mathrm{aq})}$ was quickly poured into a beaker containing $10 \mathrm{ml}$ of $0.02 \mathrm{M}$ aniline in $1.0 \mathrm{M} \mathrm{HCl}_{(\mathrm{aq})}$ under magnetic stirring. The mixed solution in the beaker was magnetically stirred for 5 minutes, after which the magnetic stirring was stopped and the polymerization was allowed to proceed in the beaker for 2 hours. After the 2-hour reaction, the reaction mixture was transferred to a dialysis tubing (Spectra/Por, 12-14,000 MW cutoff). The reaction mixture was dialyzed against 4 -L deionized water for 20 hours. The dialysis bath was changed 6 times during the course of the 20-hour dialysis. The dialyzed aqueous dispersion of PANI nanofibers was then transferred to a storage vial for future use.

A home-built, sealed apparatus used to thermally treat HCl-doped PANI nanofiber samples deposited onto glass slides in a controlled atmosphere of flowing nitrogen gas (99.99\%) is shown in Figure 1. For computer-controlled conductometric measurements (accuracy of current measurements: $\pm 100 \mathrm{pA}$ ), the same heater chamber was used, with samples of PANI nanofibers deposited onto a glass slide with pre-fabricated, addressable gold electrode lines $(\sim 2$ $\mathrm{cm} \times 5 \mu \mathrm{m}$; gap between the electrode lines: $500 \mu \mathrm{m})$. By modulating the gas-flow parameters, $\mathrm{N}_{2}$ or $1 \% \mathrm{H}_{2}$ carried by $\mathrm{N}_{2}$ was controllably delivered into the sealed gas-flow system to investigate the electrical response of $\mathrm{HCl}$-doped PANI nanofibers subject to various thermal treatments.

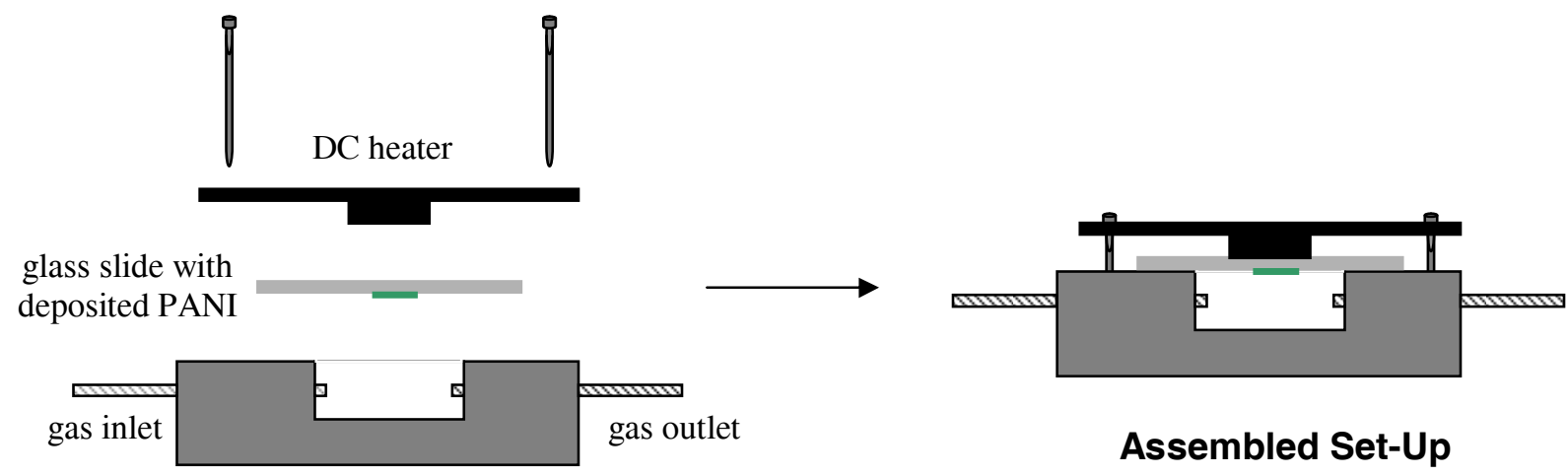

Figure 1. Schematic illustration of the home-built apparatus used for performing thermal treatments or coductometric measurements on PANI samples deposited on glass slides (not drawn to scale). 


\section{DISCUSSION}

\section{Conductometric Measurements}

The conductometric device used in this study was composed of two adjacent parallel gold electrode lines bridged by deposited HCl-doped PANI nanofibers (diameter of the sample spot: slightly $>500 \mu \mathrm{m}$ ). After the conductometric device was assembled into the experimental set-up (see Figure 1), the device was dried in $\mathrm{N}_{2}$ at $25^{\circ} \mathrm{C}$ for 12 hours. The conductometric response of the devices subject to the different thermal treatment conditions and then exposed to several cycles of $1 \% \mathrm{H}_{2}$ is shown in Figure 2. In general, after drying in $\mathrm{N}_{2}$ at $25^{\circ} \mathrm{C}$ for 12 hours, devices showed a $\sim 10 \%$ decrease (when the device transduction pattern was stabilized; same for the following discussion) in electrical resistance upon exposure to $1 \% \mathrm{H}_{2}$. However, devices subject to 12 -hour drying in $\mathrm{N}_{2}$ at $25^{\circ} \mathrm{C}$ and further thermal treatments in $\mathrm{N}_{2}$ at $100^{\circ} \mathrm{C}, 164^{\circ} \mathrm{C}$ or $200^{\circ} \mathrm{C}$ for 30 minutes showed different transduction behaviors. Specifically, devices subject to thermal treatments at $100^{\circ} \mathrm{C}$ and $164^{\circ} \mathrm{C}$ showed a decrease in electrical resistance by $\sim 7 \%$ and $<0.5 \%$, respectively. More interestingly, the device subject to the thermal treatment at $200^{\circ} \mathrm{C}$ showed a transduction behavior with opposite polarity, i.e. a $\sim 5 \%$ increase in electrical resistance upon exposure to $1 \% \mathrm{H}_{2}$. The above results indicate that the transduction behaviors of these devices can be altered by thermal treatments, and that the transduction behavior is a function of the thermal treatment temperature.

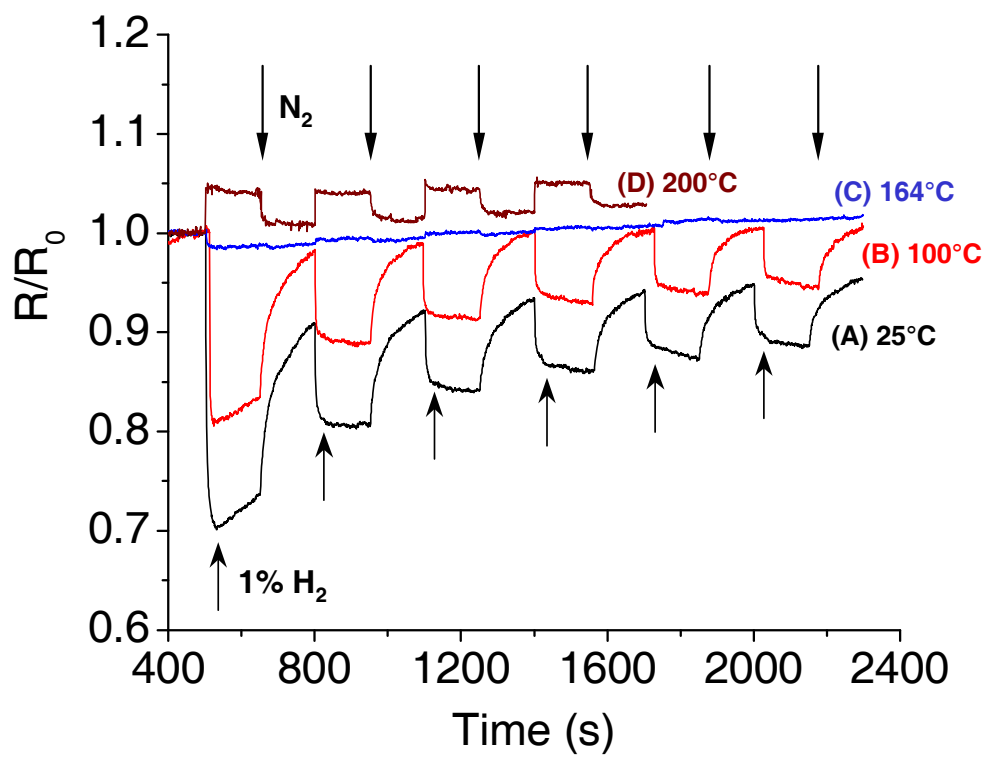

Figure 2. Conductometric response of the device subject to (A) 12-hr drying at $25^{\circ} \mathrm{C}$ in $\mathrm{N}_{2}$ with no further thermal treatment, and 12-hr drying at $25^{\circ} \mathrm{C}$ in $\mathrm{N}_{2}$ with a further 30-min thermal treatment in $\mathrm{N}_{2}$ at (B) $100^{\circ} \mathrm{C}$, (C) $164^{\circ} \mathrm{C}$, or (D) $200^{\circ} \mathrm{C}$. For (A), $\mathrm{R}_{0}$ is the stabilized resistance after 12-hr drying at $25^{\circ} \mathrm{C}$. For (B), (C) or (D), $\mathrm{R}_{0}$ is the stabilized resistance after 12-hr drying at $25^{\circ} \mathrm{C}$ followed by a 30 -min thermal treatment in $\mathrm{N}_{2}$ at $100^{\circ} \mathrm{C}, 164^{\circ} \mathrm{C}$, or $200^{\circ} \mathrm{C}$. 


\section{SEM}

SEM images of the $\mathrm{HCl}$-doped PANI nanofiber samples subject to 12-hour drying in $\mathrm{N}_{2}$ at $25^{\circ} \mathrm{C}$ with no further thermal treatment or with a further thermal treatment at $100^{\circ} \mathrm{C}, 164^{\circ} \mathrm{C}$ or $200^{\circ} \mathrm{C}$ in $\mathrm{N}_{2}$ for 30 minutes are shown in Figure 3. Although the general morphology (nanofiber mat) was not significantly changed by the employed thermal treatments, it can be seen from the figure that, upon thermal treatments, inter-fiber fusion occurred in certain areas with higher density of nanofibers.
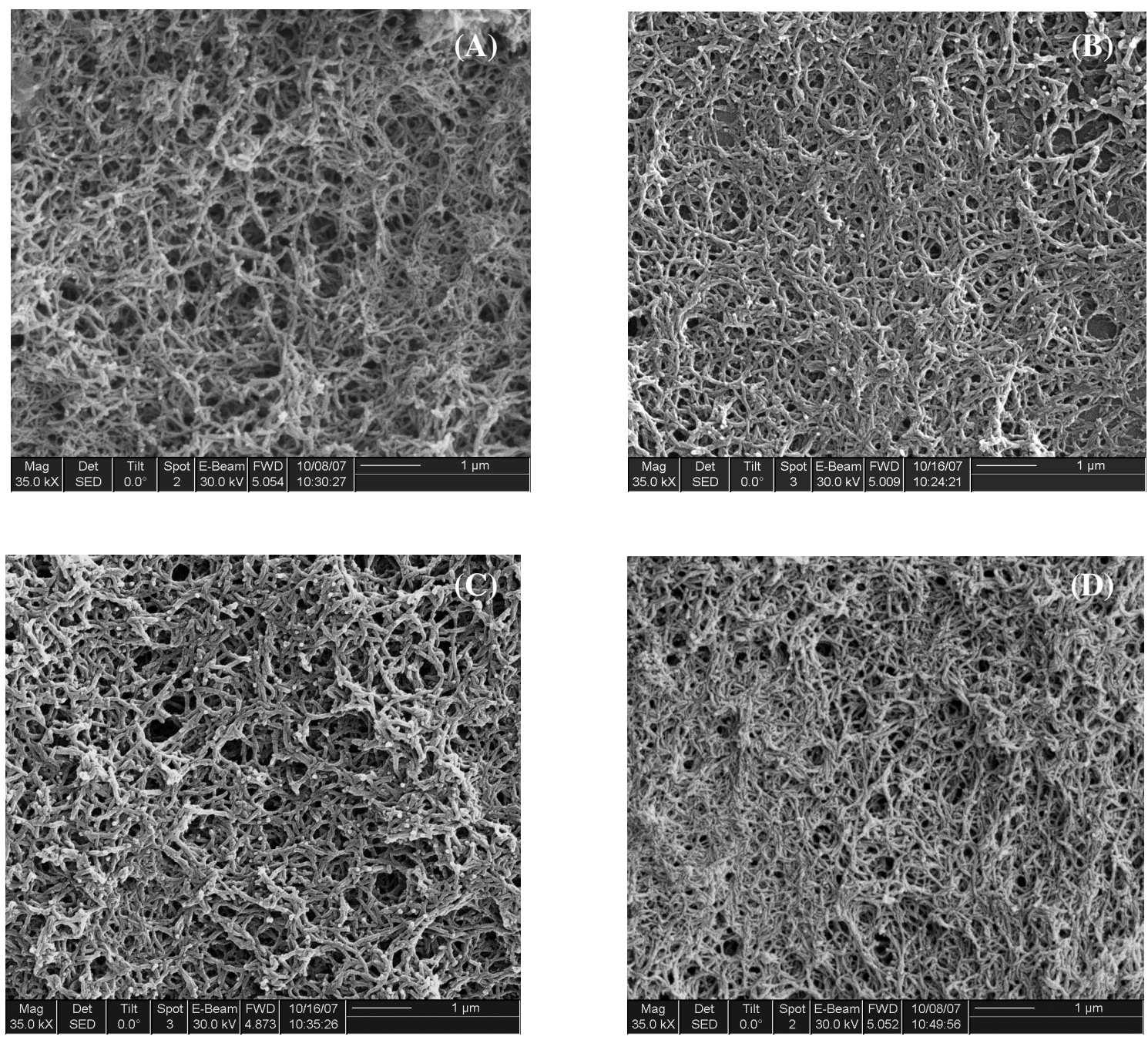

Figure 3. SEM images of $\mathrm{HCl}$-doped PANI nanofibers subject to (A) 12 -hr drying in $\mathrm{N}_{2}$ at $25^{\circ} \mathrm{C}$ with no further thermal treatment, and 12-hr drying in $\mathrm{N}_{2}$ at $25^{\circ} \mathrm{C}$ followed by a further 30 -min thermal treatment in $\mathrm{N}_{2}$ at (B) $100^{\circ} \mathrm{C}$, (C) $164^{\circ} \mathrm{C}$ or (D) $200^{\circ} \mathrm{C}$.

\section{FTIR and TGA}

Figure 4 shows the FTIR spectra of the HCl-doped PANI nanofiber samples, each subject to 12-hour drying in $\mathrm{N}_{2}$ at $25^{\circ} \mathrm{C}$ with no further thermal treatment, or with a further thermal 
treatment at $100^{\circ} \mathrm{C}, 164^{\circ} \mathrm{C}$ or $200^{\circ} \mathrm{C}$ in $\mathrm{N}_{2}$ for 30 minutes. The sample subject to 12 -hour drying in $\mathrm{N}_{2}$ at $25^{\circ} \mathrm{C}$ with no further thermal treatment gave the FTIR spectrum characteristic of HCldoped polyaniline (e.g. $1585 \mathrm{~cm}^{-1}$ - stretching of quinoid unit; $1486 \mathrm{~cm}^{-1}-$ stretching of benzenoid unit; $1295 \mathrm{~cm}^{-1}$ - aromatic C-N stretching; $1115 \mathrm{~cm}^{-1}$ - a mode of quinoid unit; 759 $\mathrm{cm}^{-1}, 698 \mathrm{~cm}^{-1}$ and $544 \mathrm{~cm}^{-1}$ - peaks associated with substituted benzene rings) $[12,13]$. The sample subject to 12 -hour drying in $\mathrm{N}_{2}$ at $25^{\circ} \mathrm{C}$ followed by a 30 -minute thermal treatment in $\mathrm{N}_{2}$ at $100^{\circ} \mathrm{C}$ still gave the FTIR spectrum with the peaks characteristic of HCl-doped PANI, but the relative intensities of those peaks changed. Our TGA study (data not shown) indicated that a major weight loss occurred when HCl-doped polyaniline was heated from room temperature to $100^{\circ} \mathrm{C}$ in $\mathrm{N}_{2}$, which is attributed to the loss of adsorbed water [14]. As the loss of adsorbed water would not significantly affect the chemical structures of polymer backbones, the change in the spectral features might be related to thermal crosslinking of polymer backbones without major degradation [15]. However, HCl-doped PANI samples subject to thermal treatments at $164^{\circ} \mathrm{C}$ or $200^{\circ} \mathrm{C}$ in $\mathrm{N}_{2}$ for 30 minutes gave dramatically different FTIR spectra. The above results indicate that $\mathrm{HCl}$-doped PANI samples subject to the thermal treatments at $164^{\circ} \mathrm{C}$ or $200^{\circ} \mathrm{C}$ in $\mathrm{N}_{2}$ for 30 minutes underwent more dramatic change in their chemical structures and/or composition. The overall FTIR study also indicates that the different transduction behaviors observed in the conductometric measurements involving $\mathrm{H}_{2}$ and $\mathrm{HCl}$-doped PANI nanofibers subject to various thermal treatments are related to the change in the chemical structure and/or composition of the HCl-doped PANI nanofiber samples.

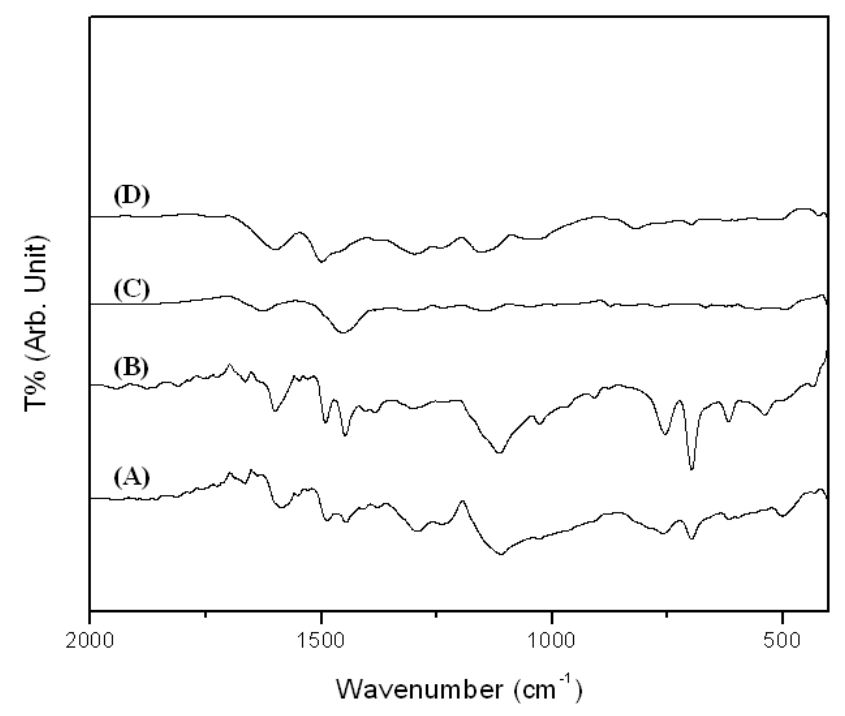

Figure 4. FTIR spectra of $\mathrm{HCl}$-doped PANI nanofibers subject to (A) 12 -hr drying in $\mathrm{N}_{2}$ at $25^{\circ} \mathrm{C}$ with no further thermal treatment, and 12 -hr drying in $\mathrm{N}_{2}$ at $25^{\circ} \mathrm{C}$ followed by a further 30 -min thermal treatment in $\mathrm{N}_{2}$ at (B) $100^{\circ} \mathrm{C}$, (C) $164^{\circ} \mathrm{C}$ or (D) $200^{\circ} \mathrm{C}$.

\section{CONCLUSIONS}

In this study, we have shown that conductometric devices integrated with HCl-doped PANI nanofibers subject to different thermal treatments can exhibit different transduction 
behaviors when exposed to $1 \% \mathrm{H}_{2}$ carried by $\mathrm{N}_{2}$. FTIR spectra indicate that the chemical structure and/or composition of the HCl-doped PANI samples can be dramatically altered by some of the employed thermal treatments. The study also suggests that the controversy in hydrogen storage studies involving conducting polymers may be related to the ambiguous thermal treatments on HCl-treated PANI samples. In addition to investigating the interactions between $\mathrm{H}_{2}$ and conducting polymers, the conductometric devices used in this study may be exploited to help systematically screening and identifying the active chemical species based on conducting polymers for hydrogen storage application. Although the interaction mechanisms between $\mathrm{H}_{2}$ and the $\mathrm{HCl}$-doped polyaniline nanofibers used in our devices were not investigated in the present work, the interesting transduction behaviors presented in this paper indeed indicate that they deserve to be studied in more detail in the future.

\section{ACKNOWLEDGMENTS}

The authors wish to acknowledge the supports from DOE (PCW and AGM; grant number: DE-FC36-05GO15075), ARO (PCW and ATCJ; grant number: W911NF-06-1-0462), NIRT (YD; grant number: ECS-0303981) and JSTO-DTRA (LAS).

\section{REFERENCES}

1. S.J. Cho, K.S. Song, J.W. Kim, T.H. Kim, K. Choo, Fuel Chemistry Division, 224th National Meeting of the American Chemical Society 47, 790 (2002).

2. S.J. Cho, K. Choo, D.P. Kim, J.W. Kim, Catal. Today 120, 336 (2007).

3. Q. Huang, C. Wei, Conference Abstract, 205th Meeting of the Electrochemical Society, San Antonio, TX, USA, May 9-14, 2004.

4. M.U. Jurczyk, A. Kumar, S. Srinivasan, E. Stefanakos, Int. J. Hydrogen Energy 32, 1010 (2007).

5. B. Panella, L. Kossykh, U. Dettlaff-Weglikowska, M. Hirscher, G. Zerbi, S. Roth, Synth. Met. 151, 208 (2005).

6. A.G. MacDiarmid, Angew. Chem. Int. Ed. 40, 2581 (2001).

7. S. Virji, R.B. Kaner, B.H. Weiller, J. Phys. Chem. B 110, 22266 (2006).

8. A.Z. Sadek, W. Wlodarski, K. Kalantar-Zadeh, C. Baker, R.B. Kaner, Sens. Actuators A 139, 53 (2007).

9. P-C. Wang, E.C. Venancio, D.M. Sarno, A.G. MacDiarmid, unpublished results (Nanofibers of polyaniline, presented by A.G. MacDiarmid at ONR Polymer Review Meeting, Arlington, VA, USA, May 5, 2004).

10. A.G. MacDiarmid, P-C. Wang, E.C. Venancio, Morphology manipulation of polymerized aniline synthesized in an aqueous medium, patent disclosure, filed September 23, 2004.

11. C.O. Baker, B.H. Weiller, R.B. Kaner, e-mail communications, May 22, 2006-June 12, 2006.

12. J. Tang, X. Jing, B. Wang, F.Wang, Synth. Met., 24, 231 (1988).

13. M.K. Traore, W.T.K. Stevenson, B.J. McCormick, R.C. Dorey, S. Wen, D. Meyers, Synth. Met., 40, 137 (1991).

14. E.C. Venancio, P-C. Wang, A.G. MacDiarmid, M.J. Heben, unpublished results.

15. Y. Sun, Ph.D. Thesis, 1991, University of Pennsylvania, Philadelphia, USA. 